\title{
Pisacano Leadership Foundation Names 2018 Pisacano Scholars
}

\section{Jane Ireland}

The Pisacano Leadership Foundation, the leadership foundation of the American Board of Family Medicine, recently selected its 2018 Pisacano Scholars. These 6 medical students follow in the footsteps of 118 scholar alumni who are practicing physicians and 17 current scholars who are enrolled in medical schools or family medicine residency programs across the country. The $\mathrm{Pi}$ sacano Leadership Foundation was created in 1990 by the American Board of Family Medicine in tribute to its founder and first executive director, Nicholas J. Pisacano, MD (1924 to 1990). Each Pisacano Scholar has demonstrated the highest level of leadership, academic achievement, communication skills, community service, and character and integrity.

Ry Garcia-Sampson is a fourth-year medical student at the Warren Alpert Medical School of

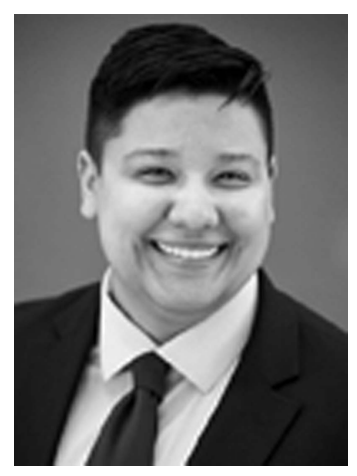
Brown University in Providence, Rhode Island. Ry is originally from $\mathrm{El} \mathrm{Paso,}$ a border town in Texas. Ry graduated from Brown University with a Bachelor of Arts in Ethnic Studies and was part of the Program for Liberal Medical Education. Ry is also currently completing a Master of Public Health at the School of Public Health at Brown University.

While an undergraduate at Brown, Ry was a Minority Peer Counselor, a Minority Peer Counselor Coordinator, and team member on the Brown Women's rugby team. As part of the Royce Fellowship, Ry conducted independent research on

Conflict of interest: The author is an employee of the American Board of Family Medicine. decreasing the health disparities gap in transplant care for Latinos through the Hispanic Transplant Program at Northwestern Memorial Hospital. At graduation Ry was awarded the Alfred Joslin Award for commitment to improving the Brown University environment.

After college Ry worked as a Nonviolence Trainer with the Institute for the Study and Practice of Nonviolence through its AmeriCorps program. In this role Ry worked with youth involved in gangs and formerly incarcerated community members to reduce violence and build resilient communities. During medical school, Ry also took a year off to work as the Diversity Fellow with the Office of Diversity and Multicultural Affairs at Brown to address issues of diversity and inclusion within the medical school and affiliated hospital partners. In this role Ry designed a leadership program to train medical students, residents, and faculty to address structural racism within medicine called the Brown Advocates for Social Change and Equity. The program is just beginning its second year and has already fostered collaborations and projects at several hospitals and community clinics across Rhode Island.

Since beginning medical school, Ry has worked on improving health care for community members who are incarcerated or formerly incarcerated with the Center for Prisoner Health and Human Rights and with physicians who work at the Rhode Island Department of Corrections. Ry has also worked with amazing social workers through the House of Hope to do outreach and assist clients experiencing homelessness in navigating the medical system. Ry is also working with trans* community members on an oral history project around health with the goal of informing medical training and improving care for trans* communities. Ry has also worked with free clinics in Rhode Island and serves as a member of the Student Health Council, which focuses on 
mental health within the medical school. Ry has received a scholarship from the Kaiser Permanente of Northern California for demonstrated commitment to underserved communities.

Ry intends to pursue a career in communitybased family medicine and work to build community partnerships to provide comprehensive primary care to underserved populations.

Joshua Pepper is in his final year of the Joint Medical Program (JMP)—a 5-year graduate/ medical degree program at the University of California (UC) -Berkeley and UC San Francisco.

Josh has always been

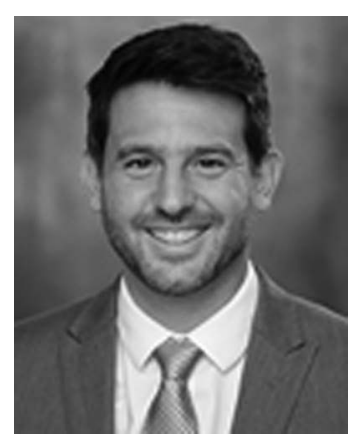
interested in the intersection of health, technology, and the environment. This passion began in high school, when he used basic mapping tools to investigate the relationship between asthma and socioeconomic status in his home town of Fresno, California. He received a $\$ 35,000$ scholarship for this research through the Robert Wood Johnson Foundation. Josh completed a dual degree undergraduate program at UC Santa Cruz and UC Berkeley, earning degrees in Environmental Studies and Civil and Environmental Engineering, respectively. He then spent several years working at Pesticide Research Institute, where he used geospatial analysis to map pesticide use patterns in rural communities of California. Josh also worked during this time as a Web site developer, data analyst, database architect, cartographer, and independent consultant. Ultimately, Josh applied to medical school to ground his analytic understanding of human health with the humanity of clinical practice.

As a medical student, Josh helped run the Suitcase Clinic, a free health center for the local underserved population. During his second year, he also planned and facilitated a weekly seminar for incoming students, where they discussed the unique challenges of providing health care to lowincome and marginally housed communities. He has also volunteered for the Ethnic Health Institute for the past 4 years, helping to screen for hypertension and diabetes at a local African Methodist Episcopal Church. Josh developed an interest in medical education while serving for 3 years as a class representative to the JMP Curriculum Committee. Since that time, he has served as a member of the JMP admissions committee, as a student advisor to the forthcoming Kaiser Permanente SOM in Southern California, and is now conducting a year-long academic project on best practices for students in longitudinal clerkships. He is also planning the 2019 curriculum for the Humanistic Elective in Activism, Reflective Transformation, and Integrative Medicine (HEART-IM), a monthlong, American Medical Student Association-sponsored elective for 25 fourth-year medical students.

Josh has carried his interest in research into medical school. For his master's thesis at the JMP, he used a novel approach of tracking the time and location of rescue asthma inhaler use to associate real-time air pollutant exposure with asthma exacerbation. He also worked for the UC Berkeley D-Lab as a student consultant, helping students across all graduate departments with geospatial analysis and data visualization. Lastly, he spent a summer in South Africa building the first online, interactive map of HIV services across 7 countries in southern Africa.

Josh is planning for a career with a multifaceted definition of physician-one that fully encompasses the scope of family medicine. Through clinical practice, he intends to hone his skills as a diagnostician and connect directly with patients and their stories. Through his research, he hopes to improve our understanding of the social and environmental determinants of health. And through advocacy, he plans to continue his work with marginalized communities and will fight to address health inequities in his community.

Emma Richardson is a fourth-year medical student at Rush Medical College in Chicago. She graduated cum laude

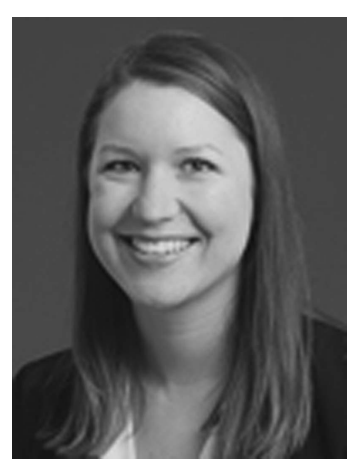
from the University of Notre Dame with a Bachelor of Science in Sociology and Pre-Professional Science.

As a college student, Emma volunteered with the Don Miller Homes in Baltimore, Maryland, working with low-income adults with HIV. 
She spent the following summer as an intern with the Foundation for International Medical Relief of Children, where she assisted with daily clinical and administrative tasks at a clinic and health organization in rural eastern Uganda, conducted an evaluation of the Community Health Educators program, and led health education sessions on nutrition, sexual health, and other topics for children at local schools and community groups. She returned to Uganda her senior year to conduct qualitative interview-based research on pathways to care for women with obstetric fistula. At Notre Dame, Emma also volunteered as a camp counselor at Camp KeS.E.M., a free summer camp for kids whose parents have or have had cancer. Throughout college, she was a mentor for a local elementary student through Notre Dame's College Mentors for Kids program, and she led the organization as the Co-President during her senior year.

After graduating from Notre Dame, Emma worked for 2 years as a project manager and physician trainer for Epic Systems, an electronic medical record software company. Through this work Emma gained insight into the operational side of medicine, including the impact of legislative, insurance-based, and compensatory guidelines and regulations on patient care and clinical workflows.

Emma is 1 of 5 students in her class selected for the Rush Family Medicine Leadership Program (FMLP), a 4-year longitudinal curriculum with clinical and didactic components for students interested in family medicine. Through the FMLP, she has had the opportunity to establish continuity of care with patients in a community-based clinic. During her first year of medical school at Rush, Emma was the primary founder of the "Correctional Health Initiative" - a student-led health education program at the Cook County Jail in Chicago. The program was designed to empower women in the jail by providing accessible, relevant health education and a forum for positive interactions with health professions students. Emma and her volunteers have led almost 200 weekly sessions with an average of 32 participants each session. During this time, she has also been involved in research with the Department of Infectious Disease, examining the co-occurring epidemics of incarceration, HIV, and MRSA colonization. Through these experiences, Emma has developed a strong interest in correctional health and care for justice-involved individuals. Emma has served in leadership roles of the Rush chapters of Students for a National Health Program and the American Medical Student Association. She is the current student president of the Illinois Academy of Family Physicians and serves on its Board of Directors. She was recently elected to the Gold Humanism Honor Society by her peers for her commitment to service and compassionate patient centered care.

Emma was a member of the Workforce Team for Family Medicine for America's Health, a collaborative organization working to improve health care in the US and demonstrate the value of primary care. In this role, Emma worked with a team of residents, students, and faculty advisors to conduct qualitative focus group-based research regarding medical student specialty choice. This research aims to identify ways to address the primary care gap by increasing student choice of family medicine.

In the future, Emma hopes to provide comprehensive primary care to individuals who have been involved with the justice system.

Michael Rose is a fourth-year medical student at the University of

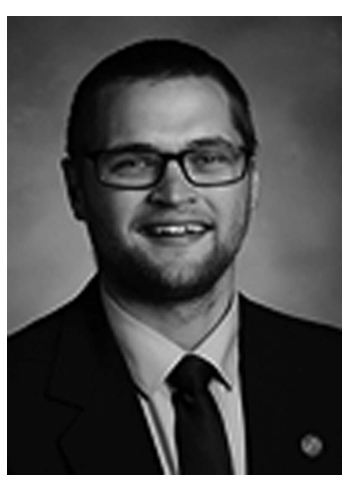
Minnesota Medical School. He graduated magna cum laude from Concordia College in Moorhead, Minnesota with degrees in Biology and Chemistry. Earlier this year he received his Master of Public Health (MPH) from the Harvard T.H. Chan School of Public Health.

Beginning in high school and throughout college, Michael worked each spring, summer, and fall as the only farm hand on a small grain farm in rural Casselton, North Dakota. As a student research assistant with the Concordia College Biology Department, Michael conducted small mammal research, designed experiments, gathered and analyzed data, and presented findings. During the following summer he volunteered with a clinic in San Lorenzo, Ecuador and with an orphanage in Shell, Ecuador. As a college student Michael also founded and operated No Food for Thought, a social justice organization based in Moorhead, Minnesota. He created the 
Web site and cocreated YouTube videos for the organization, sent bimonthly emails, and mobilized over $\$ 10,000$ in pledged donations to various nonprofit agencies. Michael was also the pitcher for the Concordia College Baseball Team during his 4 years there, served as a leader for the Health Professions Interest Club, and volunteered with the Campus Ministry Commission, Social Justice.

As a medical student Michael received the Biomedical Sciences Award, given to the 3 highest achieving students in the biomedical sciences in the first 2 years of medical school. He received the Dean Paula Temuhlen Scholarship for his academic and leadership excellence, was selected for the Gold Humanism Honor Society, and was inducted into the Alpha Omega Alpha Honor Society last year. He was 1 of 4 students selected to participate in MetroPAP, a longitudinal integrated clerkship which focuses on the provision of Family Medicine to urban, ethnically diverse, and underserved populations. As part of this program Michael organized a Minnesota health worker's petition against repealing the Affordable Care Act (ACA), signed by over 200 Minnesota health professionals, and which he delivered to the Minnesota Congressional delegation. Michael organized calling campaigns before the ACA repeal votes and had 2 of his op-eds published in the Fargo Forum. During the summer between his first and second year of medical school, Michael interned with Minnesota Congressman Rick Nolan - the first medical student to ever intern for him. He wrote policy memos and briefs to aid in the translation of the Lancet Commission findings to concrete policy implementation.

While working on his MPH at Harvard, Michael served as an advocacy volunteer with Right to Health MA. Earlier this year he won an op-ed writing contest at the Harvard Center for Primary Care and was just recently published in the New England fournal of Medicine.

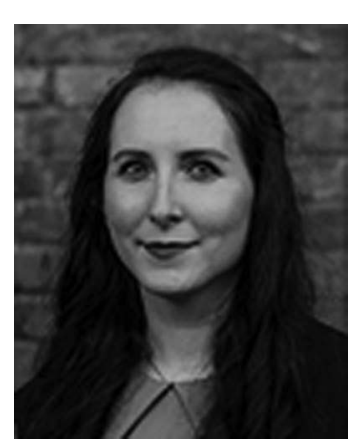

Maya Siegel is a fourth-year medical student at Johns Hopkins University School of Medicine (JHU SOM). She graduated magna cum laude with high honors from Brandeis University in Waltham, Massachusetts with a
Bachelor of Arts in Psychology and minors in Art History and Peace Conflict and Coexistence Studies. Maya recently completed her Master of Science in Evidenced Based Social Intervention and Policy Evaluation at the University of Oxford.

At Brandeis Maya received the Justice Louis Brandeis Scholarship, a 4-year full-tuition merit scholarship for academic achievement. During her senior year, she received a Brandeis Undergraduate Research Fellowship which provided research funding toward her bachelor's thesis. She was inducted into the Psi Chi Honor society and served as secretary for the group during her senior year. During college Maya was a teaching assistant in the Sociology Department, volunteered as an Emergency Medical Technician with Brandeis Emergency Medical Corps, and as an orientation leader for incoming students. She also worked as an inclusion counselor for children with special needs at a day camp. Following graduation Maya first lived in Prague for 2 years where she worked as an English teacher, a private tutor and a ghost tour guide and then lived in San Diego for 2 years where she worked on standards and guidelines within the security industry to ensure that human rights are respected by private security companies in regions of weakened governance, and volunteered with a Post-Traumatic Stress Disorder lab at the VA Hospital.

During her first year of medical school, Maya volunteered weekly as an HIV and risk reduction counselor at a local pediatric clinic, where she provided counseling related to HIV, sexually transmitted infections, contraception, and safer sex practices. She also volunteered with a student-run clinic serving uninsured residents in Baltimore and is an abortion doula and trainer with the Baltimore Doula Project. Maya has served as coleader of JHU SOM's Primary Care Interest Group and Family Medicine Interest Group, and the Hopkins Chapter of Primary Care Progress. She served on the student advisory committee for the Primary Care Leadership Track and the Advanced Ambulatory Clerkship, as Outreach Chair for the JHU SOM chapter for the American Medical Women's Association, and as coleader of the JHU SOM Jewish Student Association (JSA), the Equality and Medicine Coalition, and the Hopkins Chapter for Medical Students for Choice. She founded the Syrian Refugee Advocacy Group, which grew from a partnership between the JSA and the Muslim Student 
Association and included representatives from the School of Public Health. Maya recently joined the Hopkins Student Preceptorship Program as a mentor for first year medical students and was just selected as a SOURCE Service Scholar. This program has paired her with the Baltimore based Public Justice Center, a nonprofit civil legal service organization, and over the next several months will work on 2 outreach projects related to paid sick leave and access to health care for Medicaid recipients in Maryland. Her research interests lie in the intersection between primary care, reproductive health, and community health.

Outside of medicine, Maya's favorite hobby is improvisational comedy. She began performing improv in high school and continued while at Brandeis. She has been active in the Baltimore improv community during medical school and continues to perform as part of 2 improv groups. She also has taught improv workshops

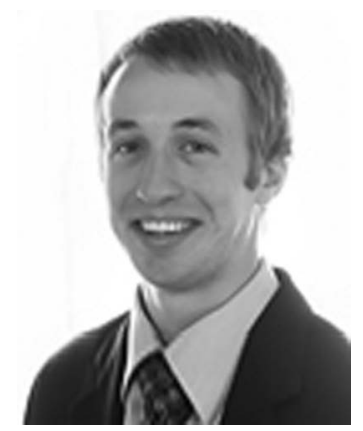
in Oxford and Baltimore.

Nick West is a fourth-year medical student at Oregon Health and Science University (OHSU). He graduated summa cum laude from Oregon State University (OSU) with a Bachelor of Science in Bioresource Research.

As an undergraduate Nick received several awards, including the OSU Waldo-Cummings Student of the Year Award 2 years in a row, the OSU College of Agricultural Sciences Outstanding Senior Award, and the OSU Presidential Award. Elected as Oregon's Future Farmers of America (FFA) State Vice President, Nick traveled over 30,000 miles in the state of Oregon, speaking and presenting workshops for agricultural education classrooms. He also traveled to China and within the United States for various leadership conferences. After retiring from his position of vice president for Oregon FFA, Nick was appointed to State Convention Director. In this volunteer position Nick oversaw all proceedings during the Oregon FFA State Convention Sessions, attended by ap- proximately 3000 students and parents. As an intern with US Congressman Greg Walden in Washington, DC during the summer of his sophomore year, Nick compiled data and records for public land timber harvests into memorandums for the Congressman. He spent 2 summers as a wildland firefighter in La Grande, Oregon, and developed a program to teach wildland firefighters and other forest service personnel in Oregon and Washington about sexual harassment awareness and prevention strategies.

At OHSU Nick developed the Family Medicine Interest Group Mentorship Program, which connects first-year medical students interested in family medicine with OHSU Family Medicine Residents. He is a founding member of the Dean's Student Rural Advisory Group, a program to help guide OHSU policy and programs for rural medical education. Through the program, he and 2 fellow classmates created the Rural Medicine Discovery Program, allowing students to visit a rural community. The visit includes dinner with hospital administrators, a clinical experience with a rural doctor, time to mentor high school students, and an afternoon to experience the area. Since 2016 Nick has been involved with a quality improvement project at a family medicine clinic, incorporating new chlamydia screening methods.

Nick was selected for a position in the Rural Scholars Program and is the only member of his class selected to participate in the Oregon FIRST program. In this program students spend their fourth year of medical school in Klamath Falls, Oregon training with the Cascades East Family Medicine Residents. The students are treated like interns and begin their own personal patient panel.

Nick grew up in rural Oregon and has worked as a ranch hand on his family's ranch since the time he was young. He plans to return to northeast Oregon to practice full-scope family medicine and continue helping with day-to-day operations on the family ranch. Rotating in medical school and growing up in this area has shed light on the high quality and robust care family doctors provide, and he is excited to one day make his own contribution.

To see this article online, please go to: http://jabfm.org/content/ 31/6/959.full. 